\title{
A Study on the Application of Electronic Management in the National Commercial Bank NCB Libya
}

\author{
Taqi Aldeen T. Mhamod Darbi, Alsedig M. A. Khanfar \\ National Commercial Bank (NCB), Tripoli, Libya \\ Email: taqialdeendarbi@gmail.com
}

How to cite this paper: Darbi, T.A.T.M. and Khanfar, A.M.A. (2020) A Study on the Application of Electronic Management in the National Commercial Bank NCB Libya. Open Access Library Journal, 7: e6596. https://doi.org/10.4236/oalib.1106596

Received: July 9, 2020

Accepted: August 9, 2020

Published: August 12, 2020

Copyright $\odot 2020$ by author(s) and Open Access Library Inc.

This work is licensed under the Creative Commons Attribution International License (CC BY 4.0).

http://creativecommons.org/licenses/by/4.0/

cc) (i) Open Access

\begin{abstract}
The aim of the paper is to identify the obstacles of the application of electronic management in the strategic planning of the National Commercial Bank NCB, the extent to which the bank employees are familiar with e-management and the extent to which e-management contributes to achieving quality requirements. The study society is limited to bank employee in NCB 10 members of the employees, the tool used is a quantitative method, and the results indicate the weakness of the application of electronic management and weak planning in the NCB from the point of view of the employees. The propose of this research is to how improve and enhance the E management in NCE and how to develop the NCB employees. In this paper I have done an interview with the NCB bank employees in order to gain information related to my study. The study emphasizes the importance of implementing electronic management as it is in line with the current technological development. The result of this study is that participants pointed to several factors which had shaped the impact of the new system (electronic management). These included: 1) the increased monitoring capacity and accountability created by the new system, allowing member staff to monitor and better communicate with each other; 2) flexibility of the system that made it easier for member staff to enter and transfer information; and 3) preparedness and collaboration between and within departments that played a key part in how staff perceived the system. Member bank staff welcoming the chance to redesign some work processes.
\end{abstract}

\section{Subject Areas}

Managerial Economics 


\section{Keywords}

E-Management, Strategic Planning, Quality Requirements, National Commercial Bank (NCB)

\section{Introduction}

The world is witnessing a tremendous development in the integration of information at several levels, which requires the introduction, use and apply in government administrative organs, where it is one of the basic resources to give the organs and its strategic weapon in dealing with the current conditions characterized by rapid change and intensified competition, not only on Local level, but also wished at the international level so that these devices can overcome all routine obstacles on the one hand and on the one hand the twin on the one hand with the nature of the times and electronic products on the other (Najem Aboud, 2004) [1]. In the light of scientific progress and the emergence of digital or electronic technology, it was necessary to the countries of the world to move towards the benefit of this technology in all areas, including administrative areas, this technology has been introduced in all administrative areas, where countries seek to apply electronic management on all their dealings to get rid of traditional management. This is called the electronic work or the paperless management. (Mohammed Alsarafie, 2007) [2]. This has made the development of management systems and organizational change one of the most important features of the modern era to keep pace with the rapid global developments and meet the challenges (Ahmad Mohammed Gonaem, 2004) [3]. And the adoption of digital management systems in line with the characteristics of the present era (Mohammed Altaiy, 2007) [4]. NCB is this institution that includes branches that provide services to meet the needs of society. Increasing the number and size of institutions of banks calls for attention to modern management methods to ensure accurate and timely access to decision-making efficiently and effectively (Saad, Ali A. Akhash (2002) [5]. These include electronic management, which aims to simplify procedures and reduce the time to provide more quality and accurate services in addition to the elimination of the negatives of traditional management such as the accumulation of paper and routine and bureaucrats administrative management (Ali Husain Bakeer, 2006) [6]. Banks and scientific research are their ability to understand and apply the principles of contemporary management and modern technologies (Pougatchev, V. and Kulkarni, A. B., 2011) [7]. However, due to the security conditions and political instability in Libya, there are no clear strategic plans in the field of information technology and the lack of adequate attention to some legislative and executive institutions to establish modern technology systems and develop a strategic plan to provide infrastructure for information and communication systems to continue to develop and build a suitable 
atmosphere (Ajliya Mohammed, 2013) [8]. This paper high light on the obstacles of the application the E management in the NCB. there are some obstacles that the employees of NCB face like administrative obstacles.

Failure to make the organizational changes required for the introduction of electronic administration, such as adding or merging some departments or divisions and determining the powers and relations between departments and the flow of work between them and financial and technical constraints the high cost of equipping the infrastructure of electronic management, which limits the progress of electronic transformation projects (Ismaeel \& Mikhai, D. Y., 2011) [9].

Lack of financial resources to establish training programs and the use of information technology expertise in the field of information technology.

Electronic illiteracy among many employees and the difficulty of communication through modern technologies. The absence of training courses and the problem of management staff and regulatory bodies in light of the transition to electronic management. Increased social disparities between the segments of society and its division led to an increase in the depth of the gap and weaker electronic management projects.

\section{Research Questions}

1) What are the views on the application of NCB staff of the electronic management?

2) What challenges exist on the application of electronic management at the $\mathrm{NCB}$ ?

\section{Methodology}

\subsection{Participants}

The participants in this study were $10 \mathrm{NCB}$ employees, they came from different bans branches in Libya. Their experience in this field ranged from a year to over to 30. Since all participants had little or no experience about the real electronic management. All interviews were carried out in a semi-structured format that asked participants ten questions in order to describe their expectations and experiences toward the new system (E-Management).

\subsection{Research Design}

Understanding the participants' e-management experiences and seeking to identify ways in which participants understand or perceive those experiences is at the heart of this research. A qualitative research style that attaches great importance to understanding the complexity of human reality rather than descriptive analysis is adopted by relying on the techniques of foundation theory (Charmaz, 2006; Silverman, 2001 [10]; Strauss \& Corbin, 1990) [11] as a means of data analysis and interviews (Gillham, 2000) [12] as a means of data generation. These techniques were selected primarily for their flexibility and would facilitate the emerging issues of encrypted data through continuous comparative analysis. 


\subsection{Data Collection}

Data was obtained mainly from interviews with 10 individual participants. The interviews were face to face and writing the notes directly during the interviews. the data analysis involved data reduction through summarizing, coding, and identifying the major clusters labeled as "categories". At the next stage common categories that recurred in the transcripts were identified. Categories that appeared to cluster together were linked together to form a theme.

\subsection{Analysis}

The researcher adopted concurrent analysis techniques, including regular conversation notes and memos kept by the researcher to write reflections about the meaning of the data, to help identify emerging themes, categories and possible relationships or patterns (Eisenhardt, 1989) [13]. These reflections assisted in the content analysis of the written interviews.

Themes were then reported and discussed during the calling with ten members. Qualitative data analysis was used to assist our analysis. Analysis occurred in three phases. First, interview transcripts were reviewed several times, searching for "recurring regularities". Second, the researcher brought together the coded interviews and field notes and looked for relationships within and across the data sources. Finally, the researcher integrated and refined the categories until themes solidified.

\subsection{Findings}

We obtained the results through analysis occurred in three phases. First, interview transcripts were reviewed several times, searching for "recurring regularities". The researcher went back and forth among transcripts until categories emerged that were consistent, yet distinct. The researcher named these categories, coded the transcripts, and placed sections in labeled folders representing each categories. Second, the researcher brought together the coded interviews and field notes and looked for relationships within and across the data sources. Finally, the researcher integrated and refined the categories until themes solidified. And the results as follows:

"One participant said that there are some obstacles that face our work such as

1) Weak planning and coordination at the level of senior management electronic management programs.

2) Failure to make the organizational changes required for the introduction of electronic administration, such as adding or merging some departments or divisions and determining the powers and relations between departments and the flow of work between them."

"Two other participant emphasized that there some political issues like-Lack of effective political will and supportive to make a qualitative leap in the transition to electronic departments and provide the necessary political support to 
convince the administrative authorities the need to apply modern technologies and keep pace with the digital age and the absence of an electronic work environment protected according to legal frameworks that define the conditions of electronic dealing, such as the absence of legal legislation prohibiting the penetration and sabotage of electronic management programs and establish penalties for the perpetrators."

"One participant said yes of course a very core question that we are suffering one and the most important factors are:

1) The high cost of equipping the infrastructure of electronic management, which limits the progress of electronic transformation projects.

2) Lack of financial resources to establish training programs and the use of information technology expertise in the field of information technology.

3) Weak financial resources allocated to electronic management projects and technical maintenance problems of electronic management programs."

"One other participant believed that the human obstacles affect so much, for instance Electronic illiteracy among many employees and the difficulty of communication through modern technologies and the absence of training courses."

"Three participant asserted that think the most security constraints is-Fear of technology and not convinced of e-transactions for fear of the prejudice and threat to the elements of security and privacy in government services so that the loss of a sense of security towards many electronic transactions and financial transactions via credit cards and this is one of the most important security constraints facing the application of management Information security, where information security is the survival of information and not deleted or destroyed."

"One participant considered that from my point of view, yes there many administrative obstacles that prevent the application of electronic management like - Lack of a clear strategic vision on the use of ICTs to serve the transition towards electronic future organizations and the administrative and organizational levels and their reliance on traditional methods and trying to adhere to the principles of traditional management."

"This requirement is linked to the need to create computers, data systems and faxes. In addition, the electronic management model involves several pillars, representing the construction of a coherent network and electronic systems that enable it to perform its various functions. Electronic management of a variety of electronic networks take different forms depending on the nature of management."

Three of participants emphasized that it is based mainly on providing the best services to the public in a work environment where the diversity of skills and competencies that are prepared for the optimal use of modern technology, which necessarily leads to a process of administrative reform as well as the elimination of routine and increase the effectiveness of administrative organs and good dealing with public service applicants in a manner that supports confidence among each of the member staff, etc. 
One participant stated that the council always look forward to applying the new system in the NCB but the obstacles that face the bank Inhibited it.

\section{Discussion}

The results of this study point to three main point where the new system of electronic management affected financial organization processes and relationships: 1) Electronic management; 2) communication and 3) work relations. Electronic management' refers to the actual performance, "communication" refers to areas such as interaction among staff and issues of responsibility and accountability involved in the actual fulfillments and "work relations" includes issues of inter-department relationships, and the roles of member staff during their work inside the NCB.

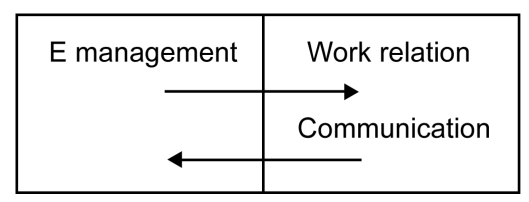

the Box presents the themes as an interlinked diagram implying that the relationship between the three categories is strongly interconnected and reflexive rather than linear. Hence the implementation of new system (electronic management has the potential to both affect and be affected by existing communication processes and work relationships Our data also describe the potential of the new system to impose changes in the organizational relationships both within and between departments. member staff and employee described the change in their workflows and how this had affected communication with other departments'.

This finding is consistent with other research in this area, which has pointed to the potential of electronic management to cause shifts in the power distributions between staff and departments [14].

Or even to foster and us versus them approach (particularly among departments which lose ownership of data entry functions as a consequence of new order entry systems.

This point is exemplified by the descriptions offered by member staff. They felt that their previously existing work relationships and communication channels had not been considered and by the electronic management processes introduced by the new system. Conversely, member staff explained that the new system (electronic management) had contributed to greater levels of accountability and reliability and provided them with the opportunity to re-shaping their administration and improve some of their work processes easily.

This study has incorporated multiple perspectives about the new system and sought wherever possible to present differing views. The general liability of its findings is restricted by the limited size of the sample and the circumstances peculiar to the bank employees. Nevertheless, the findings do have a level of simply 
communication to the bank employees and provide a useful overview to communication issues that banks are likely to confront with electronic management.

Finally, most of the participants agreed that how important the application of electronic management because it save time and money, as well as fast and easy to communicate with each other's.

\section{Conclusions}

The participants in this study pointed to several factors which had shaped the impact of the new system (electronic management).

These included: 1) the increased monitoring capacity and accountability created by the new system, allowing member staff to monitor and better communicate with each other; 2) flexibility of the system that made it easier for member staff to enter and transfer information; and 3) preparedness and collaboration between and within departments that played a key part in how staff perceived the system. Member bank staff welcoming the chance to redesign some work processes. These findings can be used to help member staff anticipate and deal with the complex variety of issues they are likely to confront. They also point to the importance of ensuring a robust interdepartmental collaboration in the planning and implementation process. This research shows that qualitative study designs can play a useful role in identifying factors that may trigger change in organizational and communication processes (Houda Abas \& Maysoom, 2015) [15].

\section{Implications}

1) Accelerating the shift towards electronic management, by moving away from the routine procedures that delay the process of transition towards electronic management.

2) Establishing training programs for Banks member staff.

3) Setting a system of motivation (material and moral) for the member staff in the field of electronic administration.

4) Improving the level of infrastructure needed to implement electronic management.

5) Development of Electronic management skills for the member staff.

6) Increase financial support for research and studies in the field of information technology.

\section{Conflicts of Interest}

The authors declare no conflicts of interest regarding the publication of this paper.

\section{References}

[1] Aboud, N. (2004) Strategic Management: Strategies, Problems and Functions. Ryid Dar Amiriekh for Publishing and Disruptions, 8, 710-810.

[2] Alsarafie, M. (2007) Electronic Management. Alessandria Dar Alfke for Publishing and Disruptions, 4, 315-418. 
[3] Gonaim, A.M. (2004) Prospects for Present and Aspirations for Future. The Arabian Library.

[4] Ataie, M. (2007) Maintenance and Manage Management Information System. Jordan Dar Almasera for Publishing and Disruptions, 10, 21-25.

[5] Ali, S. (2002) Informatics in the Saudi Development Plan. Afasal Journal, 7, 700-745.

[6] Husain, A.B. (2006) The Comprehensive Concept of Electronic Management Application. Journal Ara Haola Akhlij, 6, 602-610.

[7] Pougatchev, V. and Kulkarni, A.B. (2011) Technical Aspects of the Integrated Management Information System for Financial Institutions. International Journal of Systems Applications, Engineering \& Development, 5, 570-583.

[8] Mohammed, A. (2013) The Obstacles of Electronic Management Application. Libya Dar Aroad, 110.

[9] Ismaeel, A.G. and Mikhai, D.Y. (2011) Design of Locally E-Management System for Technical Education Foundation-Erbil. Computer Science and Telecommunications, 1, 21-28.

[10] Charmaz, K. (2001) Constructing Ground Theory: A Practical Guide through Qualitative Analysis.

[11] Strauss \& Corbin (1990) Basics of Qualitative Research: Ground Theory Procedures and Techniques. Sage, Newbury Park.

[12] Gillham (2000) The Research Interview.

[13] Eisenhardt, K.M. (1989) Building Theory for Case Study Research. Academic of Management Review, 14, 532-550.

[14] Samira, M. and Aydin (1994) The Obstacle of the Application of the Electronic Management in Human Resources Managing, Kingdom of Saudi Arabia. 109-125.

[15] Abas, H. and Maysoom (2015) The Obstacles of Application of Electronic Management in the University Libraries. Alost Ad Journal, 8, 802-811. 